\title{
Defective acid base regulation by the gall bladder epithelium and its significance for gall stone formation
}

\author{
J N Plevris, I A D Bouchier
}

Gall stone disease is a common cause of morbidity and cholecystectomy represents the most common elective abdominal operation in Western society. In the United Kingdom alone about $20 \%$ of the population may expect to develop cholelithiasis. ${ }^{1}$ Initially most research had been focused on the biochemical changes that occur in bile during gall stone formation. Recent years have seen significant advances in our knowledge and it is now recognised that the gall bladder is not a passive reservoir but has several absorptive, secretory, and motor functions, which are integrated to produce concentrated bile. The interactions between gall bladder bile and mucosa are of paramount importance to maintain the fine balance between concentration and precipitation of the biliary constituents.

The gall bladder mucosa has one of the highest rates of water absorption in the body and an $80-90 \%$ decrease in the initial volume of bile occurs within the gall bladder. This is achieved by the coupling of active sodium transport and passive water absorption resulting in isotonic fluid absorption. ${ }^{2}$ Fluid transport is subject to a variety of influences such as chronic inflammation or the presence of pharmacological agents (prostaglandins, prostacyclin, and various gastrointestinal peptides); fluid absorption is higher in daytime and is reversed to net secretion with feeding. ${ }^{3}$ Electrolyte transport has been extensively investigated; chloride is actively absorbed in exchange for bicarbonate, and potassium moves from the mucosa to the serosa according to electrochemical gradients. ${ }^{45}$ Calcium is also absorbed and its distribution across the gall bladder epithelium is of importance in the formation of gall stones. ${ }^{6}$

Liver Research

Laboratories,

Department of

Medicine, The Royal

Infirmary of

Edinburgh, Edinburgh

J N Plevris

I A D Bouchier

Correspondence to:

Dr J N Plevris, Department of Medicine, The Royal Infirmary of Edinburgh, Lauriston Place, Edinburgh EH3 9YW.

Accepted for publication 10 November 1994 be the secretion of hydrogen ions by the mucosa and it is only recently that this has been shown as a normal phenomenon in normal gall bladders. ${ }^{7}$ It has been postulated that one of the defence mechanisms of the gall bladder against calcium precipitation and gall stone formation, is the ability of the gall bladder to secrete hydrogen ions because acidifying gall bladder bile increases the solubility of calcium salts. ${ }^{6}$ Shiffman and Moore ${ }^{8}$ proposed that the diseased human gall bladder was associated with decreased acid output, but these findings were inferred from biochemical analysis of gall bladder bile obtained at laparotomy and not from direct studies on human gall bladder mucosa.

Recent studies have produced direct evidence that both the fresh human and the bovine gall bladder epithelium are capable of producing hydrogen ions. ${ }^{910}$ Acidification was reduced in inflamed gall bladders and was absent when the mucosa was non-viable. Hydrogen ion secretion was abolished when the gall bladder epithelium was exposed to sodium free mucosal solutions and in the presence of high concentrations of amiloride in the mucosal compartment. These findings suggest that hydrogen secretion in the human gall bladder depends upon a sodium/hydrogen antiport. Studies on other animal species such as rabbit, ${ }^{11}$ guinea pig, ${ }^{4}$ necturus, ${ }^{12}$ and $\operatorname{dog}^{6}$ have shown that the gall bladder epithelium is capable of acidifying the mucosal solutions in vitro and support the evidence that a sodium/hydrogen antiport is present at the apical site of the gall bladder epithelial cell.

\section{Regulation of gall bladder bile pH}

Role of mucus

The mechanisms of acid secretion by the normal human gall bladder epithelium have not been studied because of the lack of adequate number of fresh normal human tissue. We have used the bovine gall bladder as a model to study aspects of hydrogen ion secretion by the normal epithelium and have observed findings that have direct relevance to the human situation. Thus although no differences in the rate of acidification were seen between male and female animals, gall gladder bile from males was significantly more acidic compared with that from females. ${ }^{13}$ Sex is one of the most powerful influences on gall stones, which are twice as common in women during their fertile years. ${ }^{14}$ The gall bladder contains receptors for oestrogens and progesterone ${ }^{15}$ 
and it is therefore not surprising that female hormones may have a significant effect on both composition of bile and gall bladder epithelial function. Women taking oral contraceptives have cholesterol supersaturated bile. ${ }^{16} 17$ In experimental animals cholesterol supersaturated bile depresses gall bladder motility and promotes mucin hypersecretion with the resultant formation of a mucin gel adherent to the gall bladder mucosa. ${ }^{18}$ Furthermore, in animals fed a lithogenic diet, mucus hypersecretion precedes cholesterol crystal and stone formation. ${ }^{19}$ In our findings male gall bladder bile was significantly more acidic than female bile, but both male and female gall bladders showed similar acidification rates, and this suggests that the amount of mucin gel adherent to the gall bladder mucosa may be higher in the female than male gall bladder thereby reducing the diffusion of hydrogen ions through the mucus into the bile. This may result, on one hand, in a significantly acidic environment between the apical side of the epithelium and the mucin gel and, one the other, to the bile in the gall bladder lumen being alkaline. This hypothesis requires testing.

\section{Mucosal permeability}

Data from our laboratories suggest that acidification reaches a steady state around $\mathrm{pH} \mathrm{6;}$ when mucosal $\mathrm{pH}$ was set below $\mathrm{pH} 6$, acidification was reversed to alkalisation until the $\mathrm{pH}$ reached 6 (unpublished data). In most tissues the phospholipid bilayer forms the structural matrix and principal permeability barrier, which prevents dissipative back fluxes of hydrogen ions into the cell, while the tight junctions prevent the paracellular back diffusion. In addition mucus would provide another barrier. The ability of hydrogen ions to back diffuse depends upon a number of factors, such as the type of tissue and the degree of leak through the tight junctions, the presence of carrier- $\mathrm{H}^{+}$transporters and the compounds that might bind $\mathrm{H}^{+}$; for example $\mathrm{HCl}$ is a small non-polar molecule, which is formed in secretions rich in both chloride and $\mathrm{H}^{+} .20$ It seems that the gall bladder epithelium functions in such a way as to prevent the bile $\mathrm{pH}$ dropping below 6 . It becomes 'leaky' to hydrogen ions (back diffusion) when their concentration exceeds $1000 \mathrm{nmol} / \mathrm{l}$. Such a process may represent a protective mechanism to ensure that bile $\mathrm{pH}$ remains within a particular range to permit the optimum function of the biliary and pancreatic enzymes when bile enters the duodenum. In addition it has been shown that excessively acidic $\mathrm{pH}$ can induce polymerisation of calcium bilirubinate to form an insoluble polymer, which can state the process of pigment stone formation. ${ }^{18}$

\section{Hydrogen ion secretion}

The sodium/hydrogen antiport system exists in the membrane of most cells in the body and in most circumstances functions to regulate the intracellular $\mathrm{pH}$. It is of particular interest that in the case of the gall bladder epithelial cell the location of the system in the apical side (luminal) side may serve a dual function; to regulate the intracellular $\mathrm{pH}$ as well as to acidify bile. Recent studies on the human sodium antiport system have shown that the carrier protein involved is a phosphoglycoprotein of $110 \mathrm{kD}$ present as a dimer with two functional domains; a transmembrane portion of 500 residues that has all the features to catalyse amiloride sensitive $\mathrm{Na}^{+} / \mathrm{H}^{+}$exchange with a built in ' $\mathrm{H}^{+}$' sensor and a cytoplasmic regulatory domain that determines the set point value of the exchanger. The antiporter gene codes for a protein of 815 amino acids with two district domains. ${ }^{21}$ It has also been postulated that the $\mathrm{Na}^{+} / \mathrm{H}^{+}$exchanger participates in regulation of cell proliferation and activation of this transporter by mitogens may increase the intracellular $\mathrm{pH}$, which acts as a trigger for initiation of cell division. ${ }^{22}$

Fluid absorption by the gall bladder epithelium is a sodium dependant process. ${ }^{2}$ As hydrogen ion secretion is linked with sodium reabsorption, bile concentration and acidification are simultaneous phenomena. Amiloride, which inhibits acidification, also reduces the concentrating ability of the gall bladder. ${ }^{23}$

The Henderson-Hasselbalch equation is applicable to bovine gall bladder bile ${ }^{24}$ and as with canine ${ }^{6}$ and human gall bladder bile ${ }^{25}$ bicarbonate is the main buffering system. $\mathrm{PCO}_{2}$ is linearly increased as bile becomes more acidic presumably due to increased $\mathrm{CO}_{2}$ production as a result of the interaction between bicarbonate and hydrogen ion production from the gall bladder epithelium.

\section{Mechanisms of gall stone formation}

\section{Supersaturated bile}

The mechanisms associated with the formation and growth of gall stones are complex and multifactorial. The role of the gall bladder epithelium in the formation of stones is recognised to be of importance because changes in biliary composition, which may enhance lithogenicity, can be partly induced by abnormalities in gall bladder epithelial function. ${ }^{26}$ It is accepted that the sequence of events in the process of gall stone formation is supersaturation of bile, nucleation, precipitation, and subsequent growth from microcrystals to microspheroliths to gall stones. Supersaturation of bile with cholesterol is present in most patients with gall stone disease ${ }^{27}$; but $40-80 \%$ of normal subjects may have supersaturated bile in the absence of gall stones. ${ }^{28} 29$ This points to the importance of nucleation, which will be facilitated by either the presence of certain nucleating agents or the absence of the naturally occurring inhibitors of crystal formation, or both. Low molecular weight proteins delay the nucleation time and this includes the apolipoproteins $A_{1}$ and $A_{2} \cdot{ }^{30}$ In contrast high molecular weight proteins may act as nucleation promoting agents. ${ }^{31}$ Abei et $a l,{ }^{32}$ have presented evidence of $42 \mathrm{kD}$ cholesterol crystallisation promoter protein, while 
Ohya et $a l^{33}$ isolated a $130 \mathrm{kD}$ heterodimer inhibitor of cholesterol nucleation in human bile. Calcium bilirubinate or mucous glycoproteins could also serve as nucleating factors. ${ }^{34}$

While this mechanism is a classically accepted one, it does not explain why the composition of the nucleus of most cholesterol rich stones, being composed mainly by calcium salts, differs from that of the rest of the stone.

\section{Gall bladder hypomotility}

Gall bladder motility has always been considered of importance in the pathogenesis of gall stones. There is a continuous movement of bile in and out of the gall bladder and the extent rather than the rate of emptying is important in determining the degree of stasis of bile within the gall bladder. ${ }^{35}$ Gall bladder hypomotility probably precedes human cholelithiasis and contributes to the evolution of stones. ${ }^{36}$ It has been proposed that cholesterol transfer from supersaturated bile to the gall bladder wall may change the lipid composition of gall bladder smooth muscle cell membranes, which in turn might affect gene expression for the apocrine signals that influence the contractile state of the smooth muscle. ${ }^{37}$ However, the relation between reduced acidification and hypomotility is not known.

\section{Effect of hydrogen ion secretion on biliary calcium}

The role of calcium is considered to be of major relevance to the formation of both cholesterol and pigment stones. ${ }^{38-40}$ Gall bladder bile from patients with either cholesterol or pigment stones is commonly supersaturated with calcium and thus liable to calcium precipitation. ${ }^{41}$ Most gall stones contain a central core of calcium salts around which layers of either cholesterol or calcium bilirubinate are deposited as the stone enlarges. ${ }^{42}$ Pigmented gall stones are predominantly composed of the calcium salts of bilirubinate, phosphate, and long chain fatty acids and to a lesser extent carbonate. ${ }^{42-46}$ Cholesterol stones also contain calcium carbonate in their central nidus and often show peripheral calcification. In particular, calcium carbonate precipitates on the surface of the cholesterol gall stones and is present in most cholesterol gall stones. ${ }^{3}$ This suggests that calcium precipitation may be a critical initiating factor for gall stone formation and development. Biliary calcium ions reduce the solubility of biliary cholesterol, making cholesterol crystal formation more likely. ${ }^{47}$ Calcium ions stimulate mucus glycoprotein production. ${ }^{48}$ Bile $\mathrm{pH}$, the concentrating properties of the gall bladder, bicarbonate concentration, and the concentration of other ions present in bile such as sodium, chloride, and phosphate can all influence calcium concentration particularly the free ionised component $\left(\mathrm{Ca}^{++}\right) .{ }^{46}$ The regulation of calcium concentration in the gall bladder bile is therefore of critical importance. It is postulated that acid secretion may be biologically important because a reduction in the $\mathrm{pH}$ of the gall bladder bile effectively lowers the bicarbonate and reduces the risk of forming insoluble carbonate salts. As a result, the concentration of ionised calcium is increased in bile. The gall bladder epithelium, however, has the ability to absorb calcium and can reduce its concentration in bile by more than $50 \%{ }^{49}$; bile acids also buffer the remaining ionised calcium. As a consequence of these various events less calcium is available to form insoluble salts. ${ }^{39}$

\section{Calcium carbonate and calcium phosphate solubility}

The relation between bile acidification and calcium carbonate solubility has been studied in dogs. ${ }^{6}$ The findings that acidification of bile reduces the likelihood of the precipitation of calcium carbonate would be explained by $\mathrm{H}^{+}$ secretion and could prevent gall stone formation. A study of human bile, however, failed to identify differences in acidification between gall stone free subjects and patients with gall stones. $^{25}$ In that study, $80 \%$ of the patients studied had black (pigment) or mixed (containing $<30 \%$ cholesterol) stones and only $20 \%$ pure cholesterol stones. In another study using normal bovine gall bladder bile $60 \%$ of bile samples with $\mathrm{pH}>7 \cdot 10$ were supersaturated with calcium carbonate. ${ }^{24}$

Studies on the solubility of calcium phosphate salts by Moore et al ${ }^{4344}$ show that the only phosphate salt that will probably precipitate within the $\mathrm{pH}$ range of bile is $\mathrm{CaHPO}_{4}$. In contrast with calcium carbonate, $\mathrm{CaHPO}_{4}$ solubility remained high within the $\mathrm{pH}$ values seen in the bovine gall bladder bile model in all but one of the bile samples; however, the effect of acidification was still to enhance the solubility of this salt. ${ }^{24}$

The implications of the different magnitude of effect of $\mathrm{pH}$ on the solubility of the two salts may be important; a reduction in bile $\mathrm{pH}$ would proportionally decrease the formation of $\mathrm{CaCO}_{3}$ because the reaction:

$$
\left[\mathrm{CO}_{3}\right]=<=>\left[\mathrm{HCO}_{3}{ }^{-}\right]+\left[\mathrm{H}^{+}\right]<=>\mathrm{H}_{2} \mathrm{O}+\mathrm{CO}_{2}
$$

would be shifted to the right. This, in turn, would thermodynamically increase the amount of ionised calcium available for binding other anions in bile, in particular bilirubinate.

Although $\mathrm{CaHPO}_{4}$ may be soluble within the physiological $\mathrm{pH}$ range, an excess of ionised calcium if combined with increased biliary phosphate production from hydrolysis of bile phospholipids, ${ }^{4344}$ would increase the formation of calcium phosphate and precipitation of this salt, when its concentration exceeds the saturation point.

\section{Conclusion}

It seems probable, that differences in the gall bladder acidification capacity might be of importance in the process of gall stone formation; relatively more alkaline bile results in supersaturated with calcium carbonate bile, while if the bile is relatively more acidic the formation of calcium carbonate would be 
significantly reduced. This would enable calcium ions to bind bile pigments. In addition the coexistence of other factors such as cholesterol supersaturation, excess biliary phosphate or bilirubinate, the presence of nucleating factors or a deficiency in antinucleating factors $^{5051}$ all play a part in determining whether crystals precipitate and which type of gall stone is formed.

Although the current evidence suggests that the acid base status of gall bladder bile is important in the pathogenesis of gall stones and that defective hydrogen ion secretion by the epithelium significantly increases the risk of calcium salts precipitation, it is still not certain whether changes in acidification, all of which have been seen in calculous gall bladders in humans, may be secondary to the accompanying inflammation and fibrosis, or whether some of the mucosal changes are secondary to impairment of acidification and that reduced hydrogen ion secretion actually precedes gall stone formation. It is also possible that supersaturated bile, or the hydrolysis of conjugated bilirubin, or other constituents of bile such as lysolecithin, may exert an injurious effect on the mucosa with resulting reduction of acidification.

In summary, the past few years have seen more advances in the knowledge of the pathogenesis of gall stone formation. The defective acid base regulatory ability of the epithelium is another factor to be added in the long list of events participating in the formation of gall stones. Whether this understanding can be translated into therapeutic interventions remains speculative.

1 Barker DJP, Gardner MJ, Power C, Hutt MSR. Prevalence of gallstones at necropsy in nine British towns. $B M \mathcal{F} 1979$; ii: 1389-92.

2 Diamond JM. Transport mechanisms in the gallbladder. In: Code CF, ed. Handbook of physiology: alimentary canal. Washington: American Physiological Society, 1968: 2451-82.

3 Wood JR, Svanvik J. Gall-bladder water and electrolyte transport and its regulation. Gut 1983; 24: 579-93.

4 Heintz K, Petersen KU, Wood JR. Effects of bicarbonate on fluid and electrolyte transport by guinea pig and rabbit gallbladder: stimulation of absorption. $f \mathrm{Membr} \mathrm{Biol} \mathrm{1981;}$ 62: 175-81.

5 Rose RC. Absorptive functions of the gallbladder. In: Johnson LR, ed. Physiology of the gastrointestinal tract. Vol 2. New York: Raven Press, 1981: 1021-33.

6 Rege RV, Nahrwold DL, Moore EW. Absorption of biliary calcium from the canine gallbladder; protection against the formation of calcium - containing gallstones. $₹ \mathrm{Lab}$ Clin Med 1987; 110: 381-6.

7 Hussein I, Plevris JN, Harrison DJ, Hayes PC, Bouchier IAD. Impaired acidification ability of human gallbladder epithelium in patients with gallstone disease. European fournal of Gastroenterology and Hepatology 1993; 5: 935-40.

8 Shifman ML, Moore EW. Acidification of gallbladder bile is defective in patients with all types of gallstones. Gastroenterology 1984; 94: A591.

9 Plevris JN, Hayes PC, Harrison DJ, Bouchier IAD. Evidence of hydrogen ion secretion from the human gallbladder in vitro. Gut 1992; 33: 554-9.

10 Plevris JN, Hayes PC, Bouchier IAD. Mechanism of acid secretion in the bovine gallbladder epithelium. Evidence secretion in the bovine gallbladder epitheliu
of $\mathrm{Na}^{+} / \mathrm{H}^{+}$exchange. Gut 1990; 31: A1215.

11 Whitlock RT, Wheeler HO. Hydrogen ion transport by isolated rabbit gallbladder. Am $\mathcal{F}$ Physiol 1969; 17: 310-6.

12 Altenberg GA, Reuss L. Apical membrane $\mathrm{Na}^{+} / \mathrm{H}^{+}$ exchange in necturus gallbladder epithelium. $\mathcal{f}$ Gen Physiol 1990; 95: 369-92.

13 Plevris JN, Hussein I, Hayes PC, Bouchier IAD. Gallbladder acidification and bile $\mathrm{pH}$ : differences between male and female in the bovine gallbladder model. Gut 1994; 35 (suppl 5): S66.

14 Bouchier IAD. Gallstones and gender: sex differences matter. European fournal of Gastroenterology and Hepatology 1991; 3: 741-4.

15 Singletary BK, Van Thiel DH, Eagon PK. Estrogen and progesterone receptors in human gallbladder. Hepatology 1986; 6: 574-8.

16 Bennion LJ, Mott DM, Howard BV. Oral contraceptives raise the cholesterol saturation of bile by increasing biliary cholesterol secretion. Metabolism 1980; 29: 18-22.

17 Kern F Jr, Everson GT. Contraceptive steroids increase cholesterol in bile: mechanisms of action. $\mathcal{f}$ Lipid Res 1987; 28: 828-39.

18 Donovan JM, Carey MC. Formation of cholesterol gallstones. In: Bouchier IAD, Allan RN, Hodgson HJF, Keighley MRB, eds. Gastroenterology: clinical science and practice. 2nd ed. London: WB Saunders, 1993: 1702-8.

19 Lee SP, LaMont JT, Carey MC. Role of gallbladder mucus hypersecretion in the evolution of cholesterol gallstones. $\mathcal{f}$ Clin Invest 1981; 67: 1712-23.

20 Gutknecht J. Proton permeation through lipid bilayers and biological membranes. European fournal of Gastroenterology and Hepatology 1990; 2: 172-4.

21 Anwer MS, Berk PD, Suchy FJ, Wolkoff AW. Characterisation of membrane transport mechanisms: a summary of the 1991 AASLD single topic conference. Hepatology 1992; 16: 1179-93.

22 Gleeson D. Acid-base transport systems in gastrointestinal epithelia. Gut 1992; 33: 1134-45.

23 Strichartz SD, Abedin MZ, Abdou MS, Roslyn JJ. The effects of amiloride on biliary calcium and cholesterol gallstone formation. Ann Surg 1989; 209: 152-6.

24 Plevris JN, Dhariwal A, Howie AF, Dawkes RM, Chang C, Hayes PC, et al. Acid-base and electrolyte regulation in the bovine gallbladder bile model. European fournal of Gastroenterology and Hepatology 1994; 6: 47-53.

25 Martau C, Sastre B, Iconomidis N, Portugal H, Pauli AM, Gerolami A. pH regulation in human bile: study in patients with and without gallstones. Hepatology 1990; 12: patients with

26 Jacyna MR. Interactions between gallbladder bile and mucosa; relevance to gallstone formation. Gut 1990; 31: 568-70.

27 Admirand WH, Small DM. The physicochemical basis of cholesterol gallstone formation in man. $\mathcal{F}$ Clin Invest 1968; 47: 1043-52.

28 Holzbach RT, Marsh M, Olszewski M, Holan K. Cholesterol solubility in bile. Evidence that supersaturated bile is frequent in healthy man. $\mathcal{F}$ Clin Invest 1973; 52: 1467-79.

29 Hofmann AF, Grundy SM, Lachin JM, Baum RA, Hanson $\mathrm{RF}$, et al. Pretreatment biliary composition in white patients with radiolucent gallstones in the National Cooperative Gallstone Study. Gastroenterology 1982; 83: 738-52.

30 Sewell RB, Mao SJT, Kawamoto T, LaRusso NF. Apolipoproteins of high, low and very low density lipoproteins in human bile. $\mathcal{F}$ Lipid Res 1983; 24: 391-401.

31 Burnstein MJ, Ilson RG, Petrunka CN, Taylor RD, Strasberg SM. Evidence of a potent nucleating factor in the gallbladder bile of patients with cholesterol stones. Gastroenterology 1983; 85: 801-7.

32 Abei M, Kawczac P, Nuutinen H, Langnas A, Svanvik J, Holzbach RT. Isolation and characterisation of a cholesterol crystallization promoter from human bile. Gastroenterology 1993; 104: 539-48.

33 Ohya T, Schwarzendrube J, Busch N, Gresky S, Chandler $\mathrm{K}$, Takabayashi A, et al. Isolation of a human biliary glycoprotein inhibitor of cholesterol crystalisation. Gastroenterology 1993; 104: 527-38.

34 Burnstein MJ, Ilson RG, Petrunka CN, Taylor RD, Strasberg SM. Evidence of a potent nucleating factor in the gallbladder bile of patients with cholesterol stones. Gastroenterology 1983; 85: 801-7.

35 Howard PJ, Murphy GM, Dowling RH. Gallbladder emptying patterns in response to a normal meal in healthy subjects and patients with gallstones: ultrasonographic study. Gut 1991; 32: 1406-11.

36 O'Donnell LJD, Fairclough PD. Gallstones and gallbladder motility. Gut 1993; 34: 440-3.

37 LaMorte WW. Biliary motility and abnormalities associated with cholesterol cholelithiasis. Current Opinion in Gastroenterology 1993; 9: 810-6.

38 Rege RV, Moore EW, Nahrwold DL. Pathogenesis of calcium containing gallstones: relationship of total calcium and free ionised $\mathrm{CA}^{++}$in canine gallbladder and duct bile. Surg Forum 1985; 36: 132-4.

39 Moore EW. The role of calcium in the pathogenesis of gallstones. $\mathrm{Ca}^{++}$electrode studies of model bile salt solutions and other biological systems. Hepatology 1984; 4: 228-43S.

40 Moore EW. Biliary calcium and gallstone formation. Hepatology 1990; 12: 206-18S.

41 Shiffman ML, Sucermart HJ, Kellum JM, Moore EW. Calcium in human gallbladder bile. $f$ Lab Clin Med 1992; 120: 875-84.

42 Bean JM, Bills PM, Lewis D. Microstructure of gallstones. Gastroenterology 1979; 76: 548-55.

43 Moore EW, Kelley EH, Keith FB, Krell H. Pathogenesis of calcium-phosphate containing gallstones. V Saturation limits for total inorganic phosphate in bile as a function $\left[\mathrm{Ca}^{++}\right]$and pH. Gastroenterology 1989; 96: A633.

44 Moore EW, Kelley EH, Keith FB, Krell H. Pathogenesis of calcium-phosphate containing gallstones. II CaHOP4 precipitation and solubility constant products. Gastroenterology 1989; 96: A632.

45 Sutor DJ, Wilkie II. Calcium in bile and calcium salts in gallstones. Clin Chem Acta 1977; 79: 119-27.

46 Heuman DM, Moore EW, Vlahcevic ZR. Pathogenesis and dissolution of gallstones. In: Zakim D, Boyer TD, eds. 
Diseases of the liver and the biliary tree. Philadelphia: WB Saunders, 1990: 1480-516.

47 Neithercut WD. Effect of calcium, magnesium and sodium ions on in vitro nucleation of human bile. Gut 1989; 30 665-70.

48 Malet PF, Locke CL, Trotman BW, Soloway RD. The calcium ionophore A23187 stimulates glucoprotein secretion by the guinea-pig gallbladder. Hepatology 1986; 6: Conter RL, Roslyn JL, Porter-Fink V, DenBesten L.
Gallbladder absorption increases during early cholesterol

50 Sciarretta G, Ligabue A, Garuti G, Pieromaedi S, Verri A, Giacobazzi $\mathrm{G}$, et al. Inhibitory activity of gallbladder bile on calcium carbonate crystallization in vitro. Scand $\mathcal{f}$ Gastroenterol 1984; 19: 626-30.

51 Sutor DJ, Percival JM. Presence or absence of inhibitors of crystal growth in bile. I Effect of bile on the formation of calcium phosphate, a constituent of gallstones. Gut 1976; 